\title{
Comparison of Pyranometers vs. PV Reference Cells for Evaluation of PV Array Performance
}

\author{
Lawrence Dunn, ${ }^{1}$ Michael Gostein, ${ }^{1}$ and Keith Emery ${ }^{2}$ \\ ${ }^{1}$ Atonometrics, Inc., Austin, TX 78757, USA, ${ }^{2}$ National Renewable Energy Laboratory, Golden, CO \\ 80401, USA
}

\begin{abstract}
As the photovoltaics (PV) industry has grown, the need for accurately monitoring the solar resource of $P V$ power plants has increased. Historically, the PV industry has relied on thermopile pyranometers for irradiance measurements, and a large body of historical irradiance data taken with pyranometers exists. However, interest in PV reference devices is increasing. In this paper, we discuss why $P V$ reference devices are better suited for PV applications, and estimate the typical uncertainties in irradiance measurements made with both pyranometers and PV reference devices. We assert that the quantity of interest in monitoring a $\mathrm{PV}$ power plant is the equivalent irradiance under the IEC 60904-3 reference solar spectrum that would produce the same electrical response in the $P V$ array as the incident solar radiation. For PV-plant monitoring applications, we find the uncertainties in irradiance measurements of this type to be on the order of $\pm \mathbf{5 \%}$ for thermopile pyranometers and $\pm \mathbf{2 . 4 \%}$ for $\mathrm{PV}$ reference devices.
\end{abstract}

Index Terms - energy resources, instrumentation and measurement, measurement uncertainty, photovoltaic cells, calibration.

\section{INTRODUCTION}

The two most popular tools used by the photovoltaics (PV) industry for measuring irradiance are thermopile pyranometers and calibrated PV Reference Devices (PVRDs). Currently, the PV community has a poor understanding of which device is better suited for PV applications. In this work, we explain why PVRDs are better suited for PV applications, and we calculate typical measurement uncertainties for measurements made with both PVRDs and pyranometers.

Thermopile pyranometers (which we refer to in this work simply as "pyranometers") are devices that have junctions of dissimilar metals in contact with a painted black surface that absorbs solar radiation (the "hot" junction) and a separate surface that does not absorb solar radiation (the "cold" junction). They measure irradiance indirectly by measuring the temperature difference between those two surfaces [1].

Pyranometers have an essentially flat spectral response from $\sim 400$ to $\sim 2700 \mathrm{~nm}$, the transmittance of quartz. Because of this flat spectral response over a wide range of incident wavelengths, pyranometers are well suited to measure total incident shortwave radiation, independent of the spectral composition of that radiation. Pyranometer uncertainties are usually quoted with respect to the measurement of total incident solar radiation.
Unlike pyranometers, PVRDs convert incident photons to electrons through the photovoltaic effect. The efficiency of this photon-to-electron conversion is a wavelength-dependent function that is specific to various PV device technologies, and to some extent, to individual PV devices.

The Spectral Responsivity (SR) of a PV device is defined as the number of amps of current produced at its short-circuit current $\left(I_{S C}\right)$ condition for a given number of watts of incident radiation at wavelength $\lambda$. The $I_{S C}$ of a PV device is therefore given by:

$$
I_{S C}=A \int E(\lambda) \cdot S R(\lambda) d \lambda,
$$

where $A$ is the area of the PV device in $\mathrm{m}^{2}, \lambda_{1}$ and $\lambda_{2}$ are the upper and lower wavelength bounds of integration in $\mathrm{nm}$ (typically from $\sim 300$ to $\sim 1200 \mathrm{~nm}$ for a silicon PV device), $E(\lambda)$ is the spectral irradiance of the incident spectrum in $\mathrm{Wm}^{-2} \mathrm{~nm}^{-1}$, and $S R(\lambda)$ is the spectral response of the PV device in $\mathrm{AW}^{-1}$.

For PVRD calibrations performed by NREL and other PV calibration labs, the calibrated $I_{S C}$ is reported using the IEC standard 60904-3 reference solar spectrum [2] for $E(\lambda)$. Despite the calibration being reported for a single incident spectral distribution, PVRDs that are calibrated under the IEC 60904-3 reference spectrum can be used to measure irradiance under varying incident spectra. When a calibrated PVRD is illuminated by a different spectrum, the irradiance indicated by the calibrated PVRD is the irradiance as if the PVRD were illuminated by the reference spectrum. In exactly the same way, the power generated by a PV array will depend on the $E(\lambda)$ of the incident radiation and the $S R(\lambda)$ of the PV modules comprising the array.

We therefore assert that the specific irradiance quantity that best correlates to PV plant power output is the equivalent irradiance under the IEC 60904-3 reference solar spectrum that would produce the same electrical response in the PV array as the incident solar radiation. We refer to this measure of irradiance, distinct from the total solar irradiance which is independent of the spectrum of the incident light, as Irradiance $_{P V}$.

Because we assume that the quantity of most interest to a $\mathrm{PV}$ power-plant operator is the power generated by the PV array, it follows that the best and easiest way to measure Irradiance $_{P V}$ is with a calibrated PVRD with a spectral 
response that matches the spectral response of the modules comprising the PV array.

In this work, we quantify the uncertainty in representative measurements of Irradiance $_{P V}$ made with both pyranometers and PV reference devices.

For this analysis, we follow the conventions for estimating uncertainty outlined in the International Guidelines of Uncertainty in Measurement GUM (JCGM 100:2008) [3]. A detailed introduction to measurement uncertainty is beyond the scope of this paper, but we recommend Refs. [4-6] for an introduction to the GUM framework of estimating uncertainties in measurement.

As Reda [7] summarized, the GUM method of calculating measurement uncertainty can be expressed in four steps, shown in Table I.

TABLE I

GUM METHOD OF ESTIMATING UNCERTAINTIES

\begin{tabular}{|c|l|}
\hline 1 & $\begin{array}{l}\text { Determine the measurement equation, in the form } Y= \\
f\left(X_{1}, X_{2}, \ldots, X_{N}\right) .\end{array}$ \\
\hline 2 & $\begin{array}{l}\text { List or estimate the standard uncertainties, } u_{i} \text {, defined as } \\
\text { standard deviations of each input quantity, } X_{i} \text {, and of each } \\
\text { component that might introduce additional uncertainty, such } \\
\text { as interpolation, fit error, environmental conditions, etc. }\end{array}$ \\
\hline 3 & $\begin{array}{l}\text { Calculate the combined standard uncertainty using sensitivity } \\
\text { coefficients and the root-sum-of-squares (RSS) method. } \\
\text { Combine "Type A" (i.e., statistical), and "Type B" (i.e., non- } \\
\text { statistical) standard uncertainties using a RSS method. }\end{array}$ \\
\hline 4 & $\begin{array}{l}\text { Calculate the expanded uncertainty, } U, \text { and therefore the } \\
\text { confidence interval about the estimate of the output value, } Y, \\
\text { using the expression } U=k \cdot u, \text { where } k \text { is coverage factor, and } \\
\text { is calculated from known or assumed probability distributions } \\
\text { and associated degrees of freedom. }\end{array}$ \\
\hline
\end{tabular}

\section{THERMOPILE PYRANOMETERS}

Detailed pyranometer uncertainty analyses of calibrations and Global Horizontal Irradiance (GHI) measurements made with respect to total incident solar radiation have been thoroughly documented in the literature, primarily by the National Renewable Energy Laboratory (NREL) [7-9]. Reda recently published a method for calculating uncertainties in measuring shortwave solar irradiance with a thermopile pyranometer [7]. In that work, Reda assumed the availability of net-longwave radiation measurements from a pyrgeometer co-located with the thermopile pyranometer, allowing for the correction of thermal offsets effects. Here, we perform an uncertainty analysis following Reda's example, but corresponding to the irradiance defined earlier as Irradiance $_{P V}$, rather than to the total broadband irradiance, and assuming pyrgeometer data are not available, which we believe more accurately represents the typical pyranometer use case.
In the absence of pyrgeometer data, the measurement

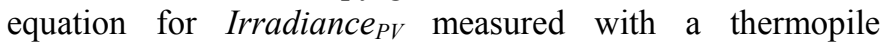
pyranometer is:

$$
\text { Irradiance }_{P V}^{P Y R}=\frac{V}{R}
$$

where the "PYR" superscript indicates measurement by a pyranometer, $V$ is the pyranometer's output voltage (usually in $\mu \mathrm{V}$ ), and $R$ is the responsivity of the pyranometer from its calibration in $\mu \mathrm{V} / \mathrm{Wm}^{-2}$. Note GHI is measured if the pyranometer is mounted perpendicular to the zenith, whereas Plane-of-Array (POA) irradiance is measured with the pyranometer co-planar with the sample in question (e.g., PV modules, building facade). We assume that for POA measurements, the pyranometer cable is facing away from the sun (e.g., north in the northern hemisphere).

\section{A. Voltage Measurement Uncertainty}

We first estimate a representative voltage measurement expanded uncertainty, expressed with a $95 \%$ confidence level. Following Reda [7], we use a representative instrument and corresponding instrument characteristics and uncertainty: a datalogger, with a listed type B expanded uncertainty of $0.07 \%$ of the reading + the offset, where the offset is $4.01 \mu \mathrm{V}$ (equal to $3 \mathrm{x}$ the resolution of $0.67 \mu \mathrm{V}+2 \mu \mathrm{V}$ ). The output voltage is assumed to have a rectangular probability distribution and an infinite number of degrees of freedom, with a corresponding coverage factor of $\sqrt{3}$ [7].

\section{B. Responsivity Measurement Uncertainty}

Our calculation of the expanded uncertainty in $R$ is listed in Table II. Note that of the sources of uncertainty in Table II, only one of them (the calibration uncertainty) would be listed in the calibration certificate of the pyranometer. Other sources of error would be specific to the measurement conditions, particular instrument used in the measurement, etc., and may be gleaned from experience or instrument manufacturer's specifications. Here, we use Reda's work in Ref. [7] as a guide for creating a representative list of the known sources and magnitudes of uncertainty of POA measurements made with a thermopile pyranometer, but include two additional sources of uncertainty: a "Spectral Mismatch with Respect to PV" error term, and a "Thermal Offset" term. The first term originates from the fact that pyranometers measure total broadband irradiance, largely independently of wavelength.

We have also eliminated an "aging per year" term, with a $0.2 \%$ contribution (assuming that the pyranometer is calibrated at least annually). Note that we do not include a response time error, although pyranometer response times are typically on the timescale of seconds, whereas PV response times are on the order of ms or less.

The "Spectral Mismatch with Respect to PV" term arises due to the mismatch between the spectral response of pyranometers and $\mathrm{PV}$ devices, as discussed in the introduction. In recent work, we have quantified this effect to 
be as high as $\sim 3 \%$ for monthly periods, and $\sim 1.5 \%$ for annual periods [10]. We use the $3 \%$ figure in Table II as a conservative estimate.

TABLE II

THERMOPILE PYRANOMETER RESPONSIVITY EXPANDED UNCERTAINTY

\begin{tabular}{|l|c|}
\hline Calibration & $3.0 \%$ \\
\hline Spectral Mismatch with Respect to PV & $3.0 \%$ \\
\hline Angular Response for $\mathrm{AOI}<30^{\circ}$ and $>60^{\circ}$ & $2.0 \%$ \\
\hline Thermal Offset & $2.0 \%$ \\
\hline Angular Alignment Error & $0.5 \%$ \\
\hline Nonlinearity & $0.5 \%$ \\
\hline Temperature Response & $1.0 \%$ \\
\hline Total (Root Sum of Squares) & $\mathbf{5 . 2 4} \%$ \\
\hline
\end{tabular}

The "Thermal Offset" error term refers to a now wellknown negative-bias error in thermopile-based pyranometer irradiance measurements [1,11]. This error is largest in pyranometers with all-black receivers. Due to the typical lack of thermal equilibrium, net energy flows exist among the sky, absorbing sensor, and pyranometer dome. This effect has been quantified as $\sim 2 \%$ at 1 -sun for all-black pyranometers, and $\sim 0.2 \%$ at 1 -sun for pyranometers with black and white absorbing sensors. Alternatively, the error can be minimized by subtracting the infrared (IR) radiative loss (i.e., thermal offset) term by measuring the long-wavelength radiation using a pyrgeometer co-located with the pyranometer [12].

The angular alignment errors are due to the uncertainties in aligning the pyranometer with the sample in the azimuthal and zenith angular directions. We assume these are limited by appropriate physical mounting mechanisms. An additional angular response error for Angles of Incidence (AOI) less than $30^{\circ}$ and higher than $60^{\circ}$ has also been included [7] because of the non-ideal angular response of pyranometers, in part due to the air gap between the sensor and dome.

\section{Details of Irradiance ${ }_{P V}^{P Y R}$ Uncertainty Calculation}

Although more complicated approaches that reduce calibration uncertainty by taking $R$ to be a function of the zenith angle have been demonstrated [13], we assume $R$ to be a constant, which we believe to be more representative of a typical pyranometer use case.

Unlike the probability distribution of $V$, we assume the probability distribution of $R$ to be normal with $\sim 500$ degrees of freedom [7], with a coverage factor corresponding to a $95 \%$ confidence interval of 1.96 [14]. With this assumption, we can calculate representative standard uncertainties for the pyranometer POA irradiance measurements made throughout the course of a representative day. For a representative pyranometer, we take the responsivity, $R\left(19 \mu \mathrm{V} / \mathrm{Wm}^{-2}\right)$, and global horizontal irradiance values from a compilation of pyranometer calibration results compiled by NREL [15]. The pyranometer is assumed to be mounted co-planar with a PV array, and Irradiance $_{P O A}$ values were calculated from the GHI values collected at NREL and given in Ref. [15], using the following expression [16]:

$$
\text { Irradiance }_{P O A}=G H I \frac{\cos \left(\theta_{A O I}\right)}{\cos \left(\theta_{\text {Zenith }}\right)},
$$

where $\theta_{\text {ZENITH }}$ is the angle between the sun and the zenith, and $\theta_{A O I}$ is the angle of incidence (i.e., the angle between the vector normal to the POA and the vector from the POA to the sun), which depends on $\theta_{\text {Zenith }}$, the angle between the plane of array and the plane perpendicular to the zenith (i.e., the tilt angle, which we take to be equal to the latitude of the PV installation), the azimuthal angle of the sun, and the azimuthal angle of the PV array [17]. In this case, the GHI data were collected in Golden, Colorado, at a latitude of $39.742^{\circ}$.

The pyranometer's output voltage values, $V$, used in uncertainty calculations were calculated by multiplying the calculated values of Irradiance $_{P O A}$ by the measured zenithangle-dependent values of $R$ throughout the course of the day, as provided in Ref. [15].

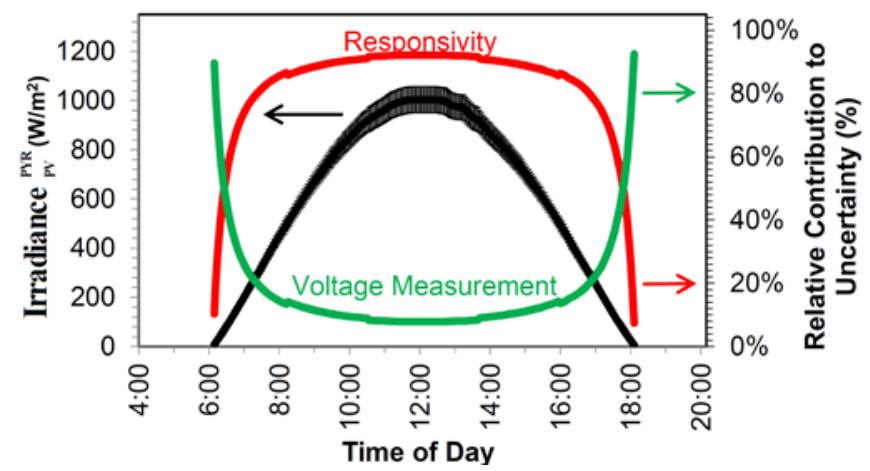

Fig. 1. Calculated POA irradiance for the pyranometer, along with accompanying expanded uncertainty error bars (left axis), and relative contributions to total uncertainty from the inputs to Eq. (2), $V$ and $R$ (right axis).

The expanded uncertainty in Irradiance ${ }_{P V}^{P Y R}$ throughout the day was calculated by multiplying the standard uncertainty throughout the day by a coverage factor of 1.96 , obtained by assuming a Student's t-distribution with an infinite number of degrees of freedom and a 95\% confidence interval [14].

Figure 1 shows the calculated values of Irradiance ${ }_{P V}^{P Y R}$ along with accompanying expanded uncertainty (shown as error bars), and the relative contributions to the total expanded uncertainty from the input quantities to the measurement equation. The relative contributions were calculated by dividing the absolute value of each $\left(c_{i} \cdot u_{i}\right)$ by the sum of the absolute values of all the $\left(c_{i} \cdot u_{i}\right)$, where the $c_{i}$ are the sensitivity coefficients and the $u_{i}$ are the standard uncertainties.

\section{PV REFERENCE DEVICES}

Within the normal range of light intensities of interest incident on a PV power plant, the $I_{S C}$ of a PV device is essentially linearly proportional to incident light intensity 
$[18,19]$. (We account for slight nonlinearities in our uncertainty budget below.) Therefore, with a properly calibrated PV device, light intensity may be measured by measuring the $I_{S C}$ of the device.

We define Irradiance ${ }_{P V}^{P V D D}$ to be Irradiance $_{P V}$ measured with a calibrated PVRD. Following the steps listed in Table I to calculate the expanded uncertainty in Irradiance $_{P V}^{P V R D}$, we start by first writing the measurement equation. Note that in the calculations shown below we assume that the spectral response of the PVRD matches the spectral response of the power-generating PV devices, so that no spectral correction is needed [20]. In this case, the measurement equation is given by:

$$
\text { Irradiance }_{P V}^{P V R D}=\frac{I_{s c, M}}{1+\alpha_{I s c}\left(T_{\text {Cell }}-T_{r e f}\right)} \frac{G_{r e f}}{I_{s c, r e f}},
$$

where $I_{s c, M}$ is the measured short-circuit current of the calibrated PV device in amps, $\alpha_{I S C}$ is the temperature coefficient of $I_{s c, M}$ in $\% /{ }^{\circ} \mathrm{C}, T_{\text {Cell }}$ is the cell temperature of the $\mathrm{PV}$ device in ${ }^{\circ} \mathrm{C}, T_{\text {ref }}$ is the reference calibration temperature of the PV device (typically $25^{\circ} \mathrm{C}$ ), $G_{\text {ref }}$ is the reference calibration irradiance of the PV device (typically $1000 \mathrm{~W} / \mathrm{m}^{2}$ ), and $I_{s c, r e f}$ is the reference short-circuit current of the PV device, in amps, at the reference temperature and reference irradiance.

\section{A. Isc Measurement Uncertainty}

Our calculation of the expanded uncertainty of $I_{s c, M}$ is shown in Table III. The uncertainty due to the measurement electronics was calculated assuming an uncertainty of $0.2 \%$ of the reading $+0.06 \%$ of the measurement scale, with the measurement scale taken to be $2 \mathrm{X}$ the value of $I_{s c, \text { ref }}$. In Table III, we have listed an uncertainty for the measurement of an Isc reading corresponding to 0.8 suns.

TABLE III

PV DEVICE I IC, $\mathrm{M}_{\text {EXPANDED UNCERTAINTY }}$

\begin{tabular}{|l|c|}
\hline Measurement Electronics (at 0.8 suns) & $0.35 \%$ \\
\hline Nonlinearity with Light Intensity & $0.30 \%$ \\
\hline Deviation of $\sim 2 \%$ of Voc from V = & $0.1 \%$ \\
\hline Angular Alignment Error & $0.5 \%$ \\
\hline Total (Root Sum of Squares) & $\mathbf{0 . 6 3} \%$ \\
\hline
\end{tabular}

We assume that the measurement electronics hold the PV device at $V=0$ (i.e., short circuit) to within $\sim 2 \%$ of the value of open-circuit voltage $(V o c)$. From experience, we list an additional uncertainty of $0.1 \%$ in $I_{s c, M}$ due to this deviation from $V=0$. We also list the uncertainty due to the nonlinearity of the PV device with light intensity, from experience, to be $0.3 \%$, and the uncertainty due to any angular alignment error to be $0.5 \%$.

We assume a rectangular probability distribution in $I_{s c, M}$ with an infinite number of degrees of freedom and a $95 \%$ confidence interval, resulting in a coverage factor of $\sqrt{ } 3$.

\section{B. Expanded Uncertainty in $\alpha_{I s c}$}

As a means of estimating the uncertainty in $\alpha_{I s c}$, we note that the European Joint Research Center European Solar Test Installation is accredited to measure temperature coefficients of PV module currents with a total expanded uncertainty of $\pm 0.016 \% /{ }^{\circ} \mathrm{C}$ [21]. A typical value of the Isc temperature coefficient of a crystalline silicon (c-Si) PV device is $0.05 \% /{ }^{\circ} \mathrm{C}[22]$. Using this value as a typical Isc temperature coefficient, the total expanded measurement uncertainty listed by ESTI is $\pm 32 \%$.

As a separate means of estimating this uncertainty, we note that the temperature coefficient of a single PV reference cell measured independently at six internationally recognized laboratories as part of the PEP 1987 reference cell and module international inter-comparison varied from 0.025 to $0.06 \% /{ }^{\circ} \mathrm{C}$, implying an uncertainty of at least $\pm 41 \%$ from the midpoint $\alpha_{I s c}$ value of $0.0425 \% /{ }^{\circ} \mathrm{C}[19]$.

Based on these data, we use as a conservative estimate an expanded uncertainty of $\pm 0.025 \% /{ }^{\circ} \mathrm{C}$ in the value of $\alpha_{I s c}$, which results in an uncertainty of $\pm 50 \%$ of the typical c-Si Isc temperature coefficient of $0.05 \% /{ }^{\circ} \mathrm{C}$. Nothing is known about the probability distribution of this input parameter, so we assume a rectangular probability distribution with an infinite number of degrees of freedom, and a $95 \%$ confidence interval, resulting in a coverage factor of $\sqrt{3}$.

\section{Expanded Uncertainty in $T_{\text {Cell }}$}

We next turn to the expanded uncertainty estimate in the cell temperature of the PVRD. As an example, we assume temperature measurements are carried out on the back surface of the PVRD with a Resistive Temperature Detector (RTD), with an associated expanded measurement uncertainty of $\pm 0.3^{\circ} \mathrm{C}$ at $0^{\circ} \mathrm{C}$ and $\pm 0.8^{\circ} \mathrm{C}$ at $100^{\circ} \mathrm{C}[23]$. We also assume the use of an RTD temperature transmitter with an associated measurement uncertainty of $\pm 0.1 \%$ of full scale [24]. Finally, we note that King et al. have found the cell temperature of a packaged PV device to be higher than the back-surface temperature of the package by $n \cdot 3^{\circ} \mathrm{C}[25]$ to $n \cdot 8^{\circ} \mathrm{C}$, where $n$ is the number of suns. Assuming the typical temperature offset is approximately known for the PVRD, we assign an additional temperature uncertainty of $3^{\circ} \mathrm{C}$ for this effect. Combining these three components using a root-sum-of-squares calculation results in an upper limit of the total expanded temperature measurement uncertainty of $\pm 3.11^{\circ} \mathrm{C}$. We assume a rectangular probability distribution and infinite number of degrees of freedom, with a corresponding coverage factor of $\sqrt{3}$.

\section{Expanded Uncertainty in $I_{s c, r e f}$}

To estimate the uncertainty in the reference short-circuit current, $I_{R e f}$, we note that NREL's expanded uncertainty with a $95 \%$ confidence interval for certified measurements of a suitable PV cell $I s c$ at $1000 \mathrm{~W} / \mathrm{m}^{2}, 25^{\circ} \mathrm{C}$, and under the reference spectrum is $\pm 1.27 \%$ [22]. 
A complete uncertainty analysis of the outdoor calibration of a secondary PV device using a calibrated PV cell from NREL results in a total expanded uncertainty in $I_{S C, R e f}$ of $\pm 2.05 \%$ to $\pm 2.17 \%$, for calibrations performed at POA irradiances above $\sim 300 \mathrm{~W} / \mathrm{m}^{2}$ [26]. We assume a constant expanded uncertainty in $I_{s c, \text { ref }}$ of $\pm 2.17 \%$ with a student's tprobability distribution and infinite number of degrees of freedom, with a corresponding coverage factor of 1.96.

\section{E. Details of Irradiance ${ }_{P V}^{P V D}$ Uncertainty Calculation}

Sensitivity coefficients were calculated by taking the first derivative of Eq. (4) with respect to each input parameter [5]. The standard uncertainties corresponding to each input parameter were calculated by dividing the listed expanded uncertainties by their corresponding coverage factors.

The same GHI data used for pyranometer uncertainty calculations were used in the calculations of the input parameters in Eq. (4) as a function of time of day. $T_{\text {Cell }}$ was estimated using the following expression from Ref. [25]:

$$
\begin{aligned}
& T_{\text {Cell }}=\left(T_{A m b}+\text { Irradiance }_{P O A} \exp (a+b \cdot W S)\right) \\
& +\left(3 \frac{\text { Irradiance }_{P O A}}{1000 \mathrm{~W} / \mathrm{m}^{2}}\right)
\end{aligned}
$$

where $T_{A m b}$ is the ambient temperature, $a$ and $b$ are phenomenological constants that depend on the type of PV device mounting (e.g., building-integrated $\mathrm{PV}$ or rackmounted), and PV device fabrication (e.g., glass/cell/glass or glass/cell/polymer) [16], and WS is wind speed. $T_{A m b}$ and $W S$ were taken from the TMY3 database [27] for the times of day, date, and location corresponding to the GHI data collected by NREL and provided in Ref. [15].

$I_{S C, M}$ was calculated as a function of time of day using Irradiance $_{P O A}$ assuming a short-circuit current temperature coefficient of $0.05 \% /{ }^{\circ} \mathrm{C}$, a value of $I_{S C, R e f}$ of $2.0 \mathrm{amps}$, and a value of $G_{R e f}$ of $1000 \mathrm{~W} / \mathrm{m}^{2}$.

For each irradiance data point throughout the day, the total standard uncertainty was calculated with reference to Eq. (4), where the input variables are $I_{S C, M}, I_{S C, \text { ref, }}, T_{M}$, and $\alpha_{I s c}$. Assuming a t-distribution with infinite degrees of freedom, we used a coverage factor of $\mathrm{k}=1.96$ (corresponding to a confidence level of $95 \%$ ) to calculate the total expanded uncertainty in Irradiance $_{P V}$ throughout the day.

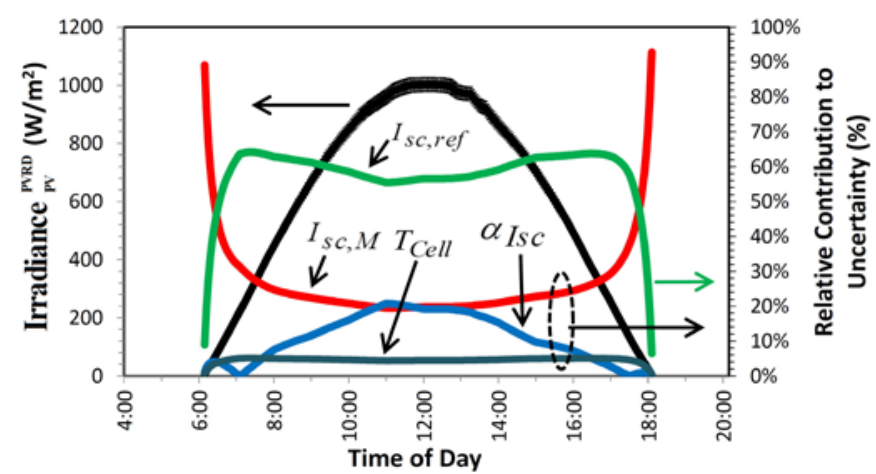

Fig. 2. Calculated POA irradiance for PV reference device, along with accompanying expanded uncertainty error bars (left axis), and relative contributions to total uncertainty from the inputs to Eq. (4).

Figure 2 shows the calculated values of Irradiance $_{P V}^{P V R D}$ along with accompanying expanded uncertainty (shown as error bars), and the relative contributions to the total expanded uncertainty from the input quantities to the measurement equation. The relative contributions were calculated by dividing the absolute value of each $\left(c_{i} \cdot u_{i}\right)$ by the sum of the absolute values of all the $\left(c_{i} \cdot u_{i}\right)$.

\section{RESULTS AND DISCUSSION}

Figure 3 shows the total expanded uncertainties in the measurements of the Irradiance $_{P V}$ made in the plane of array throughout the course of a representative day with a thermopile pyranometer and a PV reference device. Uncertainties are expressed in absolute terms $\left(\mathrm{W} / \mathrm{m}^{2}\right)$ on the left y-axis and as a percentage of Irradiance $_{P O A}$ on the right $\mathrm{y}$-axis. Figures 1 and 2 show that for pyranometers, the bulk of the measurement uncertainty is due to the uncertainty in the device's responsivity, $R$, whereas for PVRDs, the bulk of the measurement uncertainty is due to uncertainty in the reference short-circuit current value of the device, $I_{s c \text {, ref }}$.

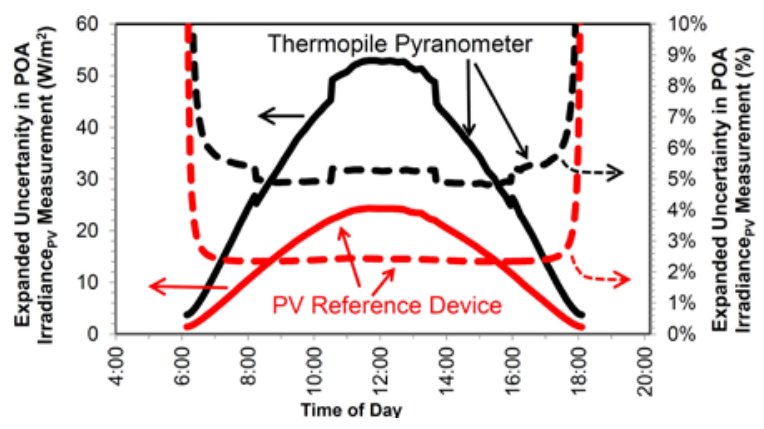

Fig. 3. Expanded uncertainties in POA irradiance measurements made with a thermopile pyranometer and PV reference device.

The PVRD achieves an expanded uncertainty that is a factor of $\sim 2$ lower than the thermopile pyranometer. During the majority of the day uncertainties are on the order of $+/-5 \%$ for a pyranometer, and $+/-2.4 \%$ for a PVRD, both stated with $95 \%$ confidence intervals. We therefore conclude that 
PVRDs provide superior irradiance measurements for PV power plant monitoring applications.

\section{ACKNOWLEDGEMENTS}

The NREL portion of this work was supported by the U.S. Department of Energy under Contract No. DE-AC36-08GO28308 with the National Renewable Energy Laboratory.

\section{REFERENCES}

[1] D. R. Myers, "Solar radiation modeling and measurements for renewable energy applications: data and model quality," Energy, vol. 30, pp. 1517-1531, 2005.

[2] "IEC 60904-3 ed2.0 - Photovoltaic devices - Part 3: Measurement Principles for Terrestrial Photovoltaic (PV) Solar Devices with Reference Spectral Irradiance Data.” IEC, 2008.

[3] "JCGM 100:2008: Evaluation of Measurement Data - Guide to the Expression of Uncertainty in Measurement." Bureau International des Poids et Mesures (BIPM), 2008.

[4] "JCGM 104:2009: Evaluation of Measurement Data - An Introduction to the 'Guide to the Expression of Uncertainty in Measurement' and Related Documents.'Bureau International des Poids et Mesures (BIPM), 2009.

[5] B. N. Taylor and C. E. Kuyatt, "Guidelines for Evaluating and Expressing the Uncertainty of NIST Measurement Results," National Institute of Standards and Technology, NIST Technical Note 1297, 1994.

[6] "Expression of the Uncertainty of Measurement in Calibration.” European co-operation for Accreditation, 1999.

[7] I. Reda, "Method to Calculate Uncertainties in Measuring Shortwave Solar Irradiance Using Thermopile and Semiconductor Solar Radiometers," National Renewable Energy Laboratory, Technical Report NREL/TP-3B10-52194, 2011.

[8] D. R. Myers, I. M. Reda, S. M. Wilcox, and T. L. Stoffel, "Uncertainty Analysis for Broadband Solar Radiometric Instrumentation Calibrations and Measurements: An Update," presented at the World Renewable Energy Congress VIII, Denver, CO, 2004.

[9] D. Myers, I. Reda, S. Wilcox, and A. Lester, "An Update on Reducing the Uncertainty in Solar Radiometric Measurements," Athens, Greece, 2005.

[10] L. Dunn and M. Gostein, "Spectral Effects in Performance Ratio Measurement: Comparing PV Reference Devices and Pyranometers," presented at the 2012 PV Module Reliability Workshop, Golden, Colorado, 2012.

[11] E. G. Dutton, J. J. Michalsky, T. Stoffel, B. W. Forgan, J. Hickey, D. W. Nelson, T. L. Alberta, and I. Reda, "Measurement of Broadband Diffuse Solar Irradiance Using Current Commercial Instrumentation with a Correction for Thermal Offset Errors," Journal of Atmospheric and Oceanic Technology, vol. 18, pp. 297-314, 2001.

[12] F. Vignola, C. N. Long, and I. Reda, "Testing a Model of IR Radiative Losses," presented at the Society of Photo-Optical
Instrumentation Engineers (SPIE) 2009 Conference, San Diego, CA, 2009.

[13] I. Reda, D. Myers, and T. Stoffel, "Uncertainty in Pyranometer and Pyrheliometer Calibrations Using GUM for NREL's ISO-17025 Accreditation Effort," presented at the IPC-XI, Davos, Switzerland, 2010.

[14] "GUM - English - Annex G. Degrees of Freedom and Levels of Confidence." [Online]. Available:

http://www.iso.org/sites/JCGM/GUM/JCGM100/C045315ehtml/C045315e_FILES/MAIN_C045315e/AG_e.html.

[Accessed: 15-May-2012].

[15] "Broadband Outdoor Radiometer Calibration Report," National Renewable Energy Laboratory, Calibration Report 960951, 2010.

[16] S. Kurtz, K. Whitfield, D. Miller, J. Joyce, J. Wohlgemuth, M. Kempe, N. Dhere, N. Bosco, and T. Zgonena, "Evaluation of High-Temperature Exposure of Rack-Mounted Photovoltaic Modules," in Proceedings of the 34th IEEE Photovoltaic Specialists Conference, Philadelphia, PA, 2009.

[17] D. L. King, "Photovoltaic Module and Array Performance Characterization Methods for All System Operating Conditions," in Proeedings of NREL/SNL Photovoltaics Program Review Meeting, Lakewood, CO, 1997.

[18] J. Nelson, The Physics of Solar Cells. Imperial College Press, 2005.

[19] J. Metzdorf, T. Wittchen, K. Heidler, K. Dehne, R. Shimokawa, F. Nagamine, H. Ossenbrink, L. Fornarini, C. Goodbody, M. Davies, K. Emery, and R. Deblasio, "The Results of the PEP '87. Round-Robin Calibration of Reference Cells and Modules,- Final Report," Braunschweig, Germany, PTB Technical Report PTB-Opt-31, Nov. 1990.

[20] C. R. Osterwald, "Translation of Device Performance Measurements to Reference Conditions," Solar Cells, vol. 18, pp. 269-279, 1986.

[21] "Joint Research Center European Solar Test Installation Accreditation Certificate," ACCREDIA: L'Ente Italiano Di Accreditamento, Accreditation Report 225 Rev. 00, 2011.

[22] K. Emery, "Uncertainty Analysis of Certified Photovoltaic Measurements at the National Renewable Energy Laboratory," National Renewable Energy Laboratory, Technical Report NREL/TP-520-45299, 2009.

[23] "RTD Elements and RTD Probes - Resistance Temperature Detection Sensors(RTDS).” [Online]. Available: http://www.omega.com/rtd.html. [Accessed: 03-May-2012].

[24] “RTD PT100 Temperature Transmitter." [Online]. Available: http://www.omega.com/pptst/TX94A-SS.html. [Accessed: 03May-2012].

[25] D. L. King, W. E. Boyson, and J. A. Kratochvil, "Photovoltaic Array Performance Model," Sandia National Laboratories, Technical Report SAND2004-3535, 2004.

[26] L. Dunn and M. Gostein, "Pyranometers vs. Reference Cells: A Complete Uncertainty Analysis.” Atonometrics, Inc., 2012.

[27] "National Solar Radiation Data Base Golden CO Data." [Online]. Available: rredc.nrel.gov/solar/old_data/nsrdb/19912005/data/tmy3/724666TY.csv. [Accessed: 07-May-2012]. 